\title{
REFLEXOS DA RESPONSABILIDADE CIVIL E PENAL NOS CASOS DE VIOLÊNCIA OBSTÉTRICA
}

\author{
REFLECTIONS OF CIVIL AND CRIMINAL LIABILITY IN \\ OBSTETRICAL VIOLENCE CASES
}

\author{
1Roberto Carvalho Veloso \\ 2Maiane Cibele de Mesquita Serra
}

\section{RESUMO}

A violência obstétrica é caracterizada pela imposição de intervenções danosas à integridade física e psicológica das parturientes, perpetrada pelos profissionais de saúde, bem como pelas instituições (públicas e privadas) nas quais tais mulheres são atendidas. O presente artigo tem por objetivo discutir a responsabilidade civil e penal nos casos dessa violência, utilizando a metodologia de análise dos acórdãos do Supremo Tribunal Federal (STF), do Superior Tribunal de Justiça (STJ) e dos Tribunais de Justiça (TJs) do Rio Grande do Sul e Minas Gerais, a fim de identificar a natureza das punições e caracterização da violência obstétrica.

Palavras-chave: Violência obstétrica, Parturientes, Direitos. mulheres, Responsabilidade

\begin{abstract}
Obstetric violence is characterized by the imposition of interventions harmful to the physical and psychological integrity of pregnant women, perpetrated by health professionals and institutions (public and private) in which such women are assisted. This paper aims to discuss the civil and criminal liability in cases of obstetric violence, from the judgments of the Supreme Court (STF), Superior Court of Justice (STJ) and the Courts of Justice (TJs) of the Rio Grande do Sul State and Minas Gerais, in order to identify the nature of the punishment and characterization of obstetric violence.
\end{abstract}

Keywords: Obstetric violence, Parturients, Rights, Women, Liability

\footnotetext{
1 Doutor e Mestre em Direito pela Universidade Federal de Pernambuco. Professor Adjunto da Universidade Federal do Maranhão. Professor Doutor do UniCeuma. Professor colaborador da UNDB. Juiz Federal,(Brasil) Email: tutortreinamento@gmail.com

2 Mestranda em Direito e Instituições do Sistema de Justiça, do Programa de Pós-Graduação em Direito da

Universidade Federal do Maranhão (PPGDIR/UFMA). Graduada em Direito e Letras. Advogada pela OAB/MA.
} 


\section{INTRODUÇÃO}

A Organização Mundial da Saúde (OMS) define violência como a imposição de um grau significativo de dor e sofrimento evitáveis. Por sua vez, a violência contra a mulher é definida pela Convenção Interamericana para Prevenir, Punir e Erradicar a Violência contra a Mulher, também conhecida como "Convenção de Belém do Pará", no seu art. $1^{\circ}$ como: "qualquer ato ou conduta baseada no gênero, que cause morte, dano ou sofrimento físico, sexual ou psicológico à mulher, tanto na esfera pública como na esfera privada". E no art. $6^{\circ}$ determina que o direito de toda mulher a ser livre de violência, abrange, entre outros, o direito a ser livre de todas as formas de discriminação, além do direito de ser valorizada e educada, livre de padrões estereotipados de comportamento e costumes sociais e culturais baseados em conceitos de inferioridade ou subordinação.

Portanto, justifica-se o estudo desse tema, a partir do pressuposto que a violência obstétrica corresponde a uma forma de violência contra a mulher e também uma forma específica da violência de gênero, uma vez que há utilização arbitrária do saber por parte de profissionais da saúde no controle dos corpos e da sexualidade das parturientes.

$\mathrm{O}$ presente trabalho possui como objetivo analisar a responsabilidade civil e penal no que tange à violência obstétrica a partir dos julgados do Supremo Tribunal Federal (STF), Superior Tribunal de Justiça (STJ) e ainda dos Tribunais de Justiça dos Estados do Rio Grande do Sul e Minas Gerais, por terem decisões mais expressivas. Diante da relevância social e jurídica do assunto, objetiva-se ainda, trazer conhecimento e propor reflexões à sociedade, em geral, em especial, aos agentes de saúde, aos agentes dos sistemas de justiça, e às parturientes, estabelecendo assim, efetiva visibilidade ao tema.

A metodologia utilizada consistiu em uma investigação de caráter exploratóriodescritivo, do tipo qualitativo, baseada principalmente na análise de casos, ou seja, das decisões proferidas nos julgamentos e contidas nos acórdãos dos respectivos tribunais a fim de identificar a natureza das punições impostas aos responsáveis pela violência obstétrica contra a mulher, bem como a sua caracterização.

Para construirmos nosso estudo, inicialmente realizamos uma busca exploratória nos sítios eletrônicos dos respectivos tribunais e ainda através do site JusBrasil para fazermos a busca no âmbito dos Tribunais de Justiça dos Estados do Rio Grande do Sul e Minas Gerais, no mês de dezembro de 2015. Utilizamos inicialmente a palavra "violência obstétrica", sem entretanto encontrar nenhum dado referente ao objeto da pesquisa. 
Posteriormente, no intuito de investigar de modo aprofundado a temática abordada, utilizamos as palavras-chave mais caracterizadoras da violência obstétrica, tais como: episiotomia, manobra de Kristeller, cesárea lesão, lesão no parto e erro médico parto.

Diante das buscas, escolhemos os julgados mais expressivos relacionados à temática. A fim de dirimir eventuais erros e ter mais precisão na amostragem, cada julgado selecionado foi analisado detalhadamente a fim de averiguar se de fato estávamos diante de uma situação caracterizadora de violência obstétrica ou perante erro médico pertinente ao parto sem liame com a modalidade de violência, e ainda distinguir as recomendações médicas baseadas em evidências científicas das condutas caracterizadoras de violência obstétrica.

A fim de aprofundar a pesquisa, utilizamos como principal referencial teórico o Dossiê elaborado pela Rede Parto do Princípio para a CPMI da Violência Contra as Mulheres intitulado: Violência Obstétrica "Parirás com dor", além de resoluções da Organização Mundial de Saúde (OMS) para explicar e caracterizar a violência obstétrica. Ademais, utilizamos alguns autores como Gagliano, Pamplona Filho, Gonçalves, bem como o próprio Código Civil e Penal para as questões atinentes a responsabilidade civil e penal.

\section{PRINCIPAIS ASPECTOS SOBRE A VIOLÊNCIA OBSTÉTRICA}

A violência obstétrica está diretamente relacionada à história do parto, e se fez presente, sobretudo, após a inserção da prática obstétrica na medicina em que o parto deixou de ser um episódio natural, compartilhado apenas no seio familiar, para se tornar uma espécie de evento no ambiente hospitalar, prática dominada pela medicina e institucionalizada nos hospitais. Também conhecida como violência institucional na atenção obstétrica, a violência obstétrica caracteriza-se pela:

[...] violência cometida contra a mulher grávida, e sua família em serviços de saúde durante a assistência ao pré-natal, parto, pós-parto, cesárea e abortamento. Pode ser verbal, física, psicológica ou mesmo sexual e se expressa de diversas maneiras explícitas ou veladas. Como outras formas de violência contra a mulher, a violência obstétrica é fortemente condicionada por preconceitos de gênero. (PARTO DO PRINCÍPIO, 2014, p. 11).

As leis da Venezuela ${ }^{1}$ e da Argentina $^{2}$, onde a violência obstétrica é tipificada, enfatizam que essa modalidade de violência caracteriza-se pela apropriação do corpo e dos processos reprodutivos da mulher pelos profissionais de saúde, mediante um tratamento

\footnotetext{
${ }^{1}$ Lei Orgânica sobre o Direito das Mulheres a uma Vida Livre de Violência, de novembro de 2007.

${ }^{2}$ Lei Nacional n 26.485, de Proteção Integral para Prevenir, Punir e Erradicar a Violência contra as Mulheres nos Âmbitos em que se Desenvolvem suas Relações Interpessoais, vigente na Argentina desde 2009.
} 
desumanizado, abuso de medicalização e patologização dos processos naturais, causando a perda de autonomia da parturiente e da capacidade de decidir livremente sobre seu corpo e sexualidade, o que traz consequências negativas e desastrosas na qualidade de vida das mulheres.

O Brasil não possui legislação específica sobre a temática, apenas abordagem genérica. No entanto, está em tramitação no Congresso Nacional, o Projeto de Lei 7.633/2014, que dispõe sobre a humanização da assistência à mulher e ao neonato durante o ciclo gravídico-puerperal e dá outras providências, como a erradicação da violência obstétrica.

Como sujeito de direitos, a parturiente possui uma série de direitos, tais como: a dignidade da pessoa humana (art. $1^{\circ}$, III, CRFB/88) como fundamento do Estado Democrático de Direito; o princípio da igualdade (art. $5^{\circ}, \mathrm{I}, \mathrm{CRFB} / 88$ ) que a protege de todas as formas de discriminação; o princípio da legalidade (art. 5, II, CRFB/88) que assegura autonomia à mulher; e ainda a proteção à vida, à saúde (acesso, segurança), à maternidade e à infância (Princípio da Beneficência).

Entretanto, tais direitos e prerrogativas têm sido amplamente desrespeitados, uma vez que uma em cada quatro mulheres sofre violência obstétrica, conforme pesquisa realizada pela Fundação Perseu Abramo,

Segundo a OMS, muitas intervenções aplicadas rotineiramente são consideradas como fator de risco para a mulher e para o neonato. Ademais, coexistem crenças e preconceitos no que concerne à sexualidade e saúde das mulheres numa sociedade tipicamente patriarcal que contribuem sobremaneira diante da forma como elas são vistas e (des) tratadas pelos profissionais da saúde. Consoante a organização:

Todas as mulheres têm direito ao mais alto padrão de saúde atingível, incluindo o direito a uma assistência digna e respeitosa durante toda a gravideze o parto, assim como o direito de estar livre da violência e discriminação. Os abusos, os maus tratos, a negligência e o desrespeito durante o parto equivalem a uma violação dos direitos humanos fundamentais das mulheres, como descrevem as normas e princípios de direitos humanos adotados internacionalmente. Em especial, as mulheres grávidas têm o direito de serem iguais em dignidade, de serem livres para procurar, receber e dar informações, de não sofreremdiscriminações e de usufruírem do mais alto padrão de saúde física e mental, incluindo a saúde sexual e reprodutiva. (OMS, 2014, p. 01)

Desta forma, percebe-se que tal modalidade de violência tem perdurado ao longo da história e na atualidade ganhou caráter endêmico, uma vez que está cotidianamente presente nas comunidades e países de todo o mundo, independentemente da classe social, raça, idade, sexo ou religião. Em distintas partes do mundo, a violência obstétrica tem se alastrado de maneira preocupante e silenciosa, haja vista que as mulheres vítimas desta prática não a percebem como tal. Por questões culturais, o parto ainda é encarado como um momento de "dor necessária". 
A violência obstétrica enseja em séria lesão aos direitos da mulher, gerando danos físicos, psicológicos e sexuais às parturientes. Não obstante a outras formas perpetradas de violência obstétrica, as situações violadoras mais comuns são: a recusa de admissão em hospital ou maternidade, gerando a chamada peregrinação por leito; impedimento da entrada do acompanhante escolhido pela mulher; aplicação de soro com ocitocina para acelerar o trabalho de parto; episiotomia de rotina; manobra de Kristeller; cesáreas eletivas; restrição da posição do parto; violência psicológica por meio de humilhações, situações vexatórias, grosseria e comentários ofensivos; além de outros procedimentos dolorosos, desnecessários e humilhantes, tais como: uso rotineiro de lavagem intestinal (enema), retirada dos pelos pubianos (tricotomia), posição ginecológica com portas abertas, exames de toque sucessivos e por pessoas diferentes para verificar a dilatação, privação de alimentos e água, imobilização de braços e pernas, etc.

A episiotomia caracteriza-se por um procedimento cirúrgico realizado pelos médicos para aumentar a abertura do canal vaginal, cortando a entrada da vagina com uma tesoura ou bisturi, algumas vezes sem anestesia.

Outra situação caracterizadora da violência obstétrica, a manobra de Kristeller que consiste numa manobra na parte superior do útero, durante as contrações do parto, visando empurrar o nascituro em direção à pelve a fim de acelerar o trabalho de parto. Utiliza-se as mãos, braço, antebraço, joelho, e em casos mais absurdos as pessoas sobem em cima do abdômen da parturiente.

Mais uma circunstância evidenciada é a cesárea eletiva, ou seja, realizada sem necessidade clínica, podendo ser agendada e feita conforme a conveniência médica, antes mesmo do início do trabalho de parto.

Nesse sentido, conforme citado anteriormente, embora o Brasil não possua legislação específica sobre a temática, nada impede que os aplicadores do Direito possam punir a prática, uma vez que resta caracterizada a violação de princípios e direitos basilares do Estado Democrático de Direito.

No intuito de compreender melhor a temática da responsabilidade civil e penal no que tange à violência obstétrica, analisaremos subsequente, os principais aspectos decorrentes deste dever de indenizar quando caracterizado o dano. 


\section{RESPONSABILIDADE CIVIL X RESPONSABILIDADE PENAL}

A responsabilidade seja na esfera civil ou penal pressupõe ato ilícito. E o ilícito, de acordo com sua natureza e grau gera como consequência uma sanção que pode ser de natureza punitiva ou ressarcitória. A obrigação, surge, portanto, como forma de responsabilizar os indivíduos pelas atividades danosas provocadas.

A responsabilidade penal decorre de um fato criminoso, seja de forma comissiva ou omissiva. Não haverá reparação e sim, aplicação de uma pena pessoal e intransferível à figura do transgressor, tendo em vista a gravidade do ilícito, uma vez que essa modalidade de responsabilidade visa a ordem social e também a punição.

A responsabilidade civil é marcada por um dano ocasionado pela lesão de um bem juridicamente tutelado, sem, contudo, haver uma prática criminal. Neste caso, haverá reparação do dano (patrimonial ou moral) por meio de uma indenização ou compensação.

Diante das considerações, a conduta do médico que pode ser ativa ou passiva (por ação ou omissão) quando danosa, pode gerar responsabilidade na esfera civil ou penal - ou ambas. (ITURRASPE apud KFOURI NETO, 2013).

Entretanto, importante considerar que o ilícito civil se distingue do penal em outros pontos. Enquanto o ilícito civil é cometido pelo agente que, por ação ou omissão age de maneira voluntária com negligência, imprudência ou imperícia; o ilícito penal é cometido pelo agente que por ação ou omissão culpável, viola uma conduta tipificada pelo Direito Penal, contrariando um tipo penal específico (numerus clausus).

Ambas as responsabilidades possuem o mesmo fundamento: restauração da ordem social. Salientamos, outrossim, que a responsabilidade penal apesar das distinções supracitadas, possui fundamentos semelhantes a responsabilidade civil, razão pela qual iremos nos ater somente à caracterização da responsabilidade civil.

\subsection{CARACTERIZAÇÃO DA RESPONSABILIDADE CIVIL}

A responsabilidade civil classifica-se em: responsabilidade civil objetiva e responsabilidade civil subjetiva. A responsabilidade civil subjetiva decorre de dano causado em função de um ato doloso ou culposo. A culpa, nesse sentido, é o principal pressuposto para a caracterização dessa modalidade de responsabilidade, em que o agente causador do dano atua com negligência, imprudência ou imperícia, conforme se pode extrair do art. 186 do Código Civil de 2002, doravante CC/2002. ${ }^{3}$ 
Entretanto, há hipóteses em que não há necessidade de comprovação de culpa, o que caracteriza-se como responsabilidade civil objetiva. Nessa espécie de responsabilidade, o dolo ou culpa na conduta do agente causador do dano é irrelevante juridicamente, haja vista que faz-se necessário somente a existência do nexo de causalidade entre o dano e a conduta do agente causador do ato ilícito, para que assim surja o dever de indenizar.

A teoria da responsabilidade civil objetiva é fundada diretamente no risco da atividade exercida pelo agente. A teoria do risco busca justificar a responsabilidade objetiva, desta forma, aquele que exerce uma atividade perigosa deve assumir os riscos e reparar o dano dela decorrente, ainda que haja isenção de culpa. Assim, surge o dever de reparação independentemente da comprovação de dolo ou culpa.

Nesse sentido, a ideia de responsabilidade civil transmuda-se da noção de culpa para a ideia de risco. Tal risco chamado de risco-proveito se configura na responsabilidade daquele que tira alguma espécie de proveito ou vantagem do fato causador do dano, tendo, portanto, obrigação de repará-lo, respondendo assim, de forma objetiva. Assim expressa o parágrafo único do art. 927 do CC/2002, ao estabelecer que:

Haverá obrigação de reparar o dano, independentemente de culpa, nos casos especificados em lei, ou quando a atividade normalmente desenvolvida pelo autor do dano implicar, por sua natureza, risco para os direitos de outrem.

Conforme doutrina majoritária e analisando o art. 186 do CC/2002 mencionado alhures, podemos extrair os seguintes elementos da responsabilidade civil: conduta humana (positiva ou negativa); dano ou prejuízo e nexo de causalidade.

\subsection{RESPONSABILIDADE PENAL: TIPOS PENAIS APLICÁVEIS NOS CASOS DE VIOLÊNCIA OBSTÉTRICA}

Conforme expresso no art. 935 do CC/2002, a responsabilidade civil é independentemente da criminal. Desta forma, o Direito Penal define uma série de crimes que podem ser cometidos pelos agentes de saúde no exercício da profissão. Com relação à violência obstétrica, os crimes mais "elementares" que podem ser imputados aos profissionais de saúde são: homicídio, lesão corporal, constrangimento ilegal, ameaça, maus-tratos, calúnia, difamação e injúria.

\footnotetext{
3 "Aquele que, por ação ou omissão voluntária, negligência ou imprudência, violar direito ou causar dano a outrem, ainda que exclusivamente moral, comete ato ilícito".
} 
O homicídio simples (art. 121, Código Penal) culposo possui pena de 6 a 20 anos. Nesse caso, considera-se dolo não apenas a intenção de causar dano (dolo direto), mas ainda as condutas em que o agente não quer o resultado morte, mas assume o risco de produzi-lo (dolo eventual). Na prática médica, o dolo eventual é caracterizado quando há imprudência e negligência que são condutas graves, e, portanto, não pode ser aplicada a pena reduzida do crime culposo.

Outro crime que merece destaque nas práticas de violência obstétrica é a lesão corporal, tipificada no art. 129, Código Penal ${ }^{4}$. Desta forma, nas práticas obstétricas, a episiotomia sem autorização da parturiente pode ser enquadrada nessa conduta, ou ainda os excessivos exames de toque praticado por diferentes pessoas como meio para práticas acadêmicas, tendo em vista que além da produção do dano no corpo da vítima, uma vez que teve a sua integridade física violada, engloba também qualquer alteração prejudicial à sua saúde que pode acarretar problemas psicológicos.

Além disso, na violência obstétrica é comum a perda de autonomia da parturiente, obrigada em muitas situações a práticas das quais não concorda, como nos casos de episiotomia, escolha do tipo de parto e da posição mais adequada para dar à luz, uso de fórceps, dentre outras práticas já citadas. Nesses casos, cabe tipificação do art. 146, Código Penal: “Constranger alguém, mediante violência ou grave ameaça, ou depois de the haver reduzido, por qualquer outro meio, a capacidade de resistência, a não fazer o que a lei permite, ou a fazer o que ela não manda". Cabe pena de detenção de três meses a um ano, ou multa.

Merece ainda prosperar o crime de ameaça, tipificado no art. 147, Código Penal ${ }^{5}$. A ameaça, infelizmente perpetrada nos casos de violência obstétrica, visa intimidar e amedrontar as gestantes mediante promessa de causar-lhe mal injusto e grave. O mau injusto é aquele que a vítima não está obrigada a suportar, podendo ser ilícito ou simplesmente imoral. Já o mal grave é o capaz de produzir ao ofendido um prejuízo relevante. (MASSON, 2012).

Outra reclamação comum nos relatos de violência obstétrica é pertinente aos maustratos (art. 136, Código Penal)6. O crime é de forma vinculada, pois a conduta somente se admite nos modos de execução expressamente previstos em lei. A parturiente, objeto de violência obstétrica, por muitas vezes tem privação de alimentos e água por longos períodos, mesmo após o parto e em algumas situações não tem os cuidados indispensáveis e especiais.

\footnotetext{
${ }^{4}$ Ofender à integridade corporal ou a saúde a outrem [...]", podendo ser de natureza leve (detenção, de 3 meses a 1 ano), grave (reclusão de 1 a 5 anos), gravíssima (reclusão de 2 a 8 anos), seguida de morte (reclusão de 4 a 12 anos) de modo doloso ou culposo ( 2 meses a 1 ano).
} 
Além das condutas expressas, muitas parturientes estão suscetíveis a sofrer calúnia (art. 138, Código Penal) ${ }^{7}$, difamação (art. 139, Código Penal) ${ }^{8}$ e injúria (art. 140, Código Penal) ${ }^{9}$.

Desta forma, feitas tais considerações a fim de elucidar de maneira mais clara os tipos penais que podem estar presentes em situações de violência obstétrica, passaremos a analisar a temática da responsabilidade civil e penal com análise dos acórdãos.

\section{RESPONSABILIDADE CIVIL E PENAL NOS CASOS DE VIOLÊNCIA OBSTÉTRICA}

A violência obstétrica pode ser perpetrada tanto pelos agentes de saúde no desempenho de atividade médico-hospitalar, quanto pelo estabelecimento de saúde.

Para apuração da responsabilidade civil dos médicos e enfermeiros deve haver verificação da culpa, assim só haverá responsabilização se comprovado que tenham agido com negligência, imprudência e imperícia, conforme o art. $14, \S 4^{\circ}$ do Código de Defesa do Consumidor: "a responsabilidade pessoal dos profissionais liberais será apurada mediante a verificação de culpa".

A concepção da responsabilidade civil subjetiva pelos danos causados na atividade médica lato sensu encontra guarida também no art. 951 do CC/2002, in verbis:

O disposto nos arts. 948, 949 e $950^{10}$ aplica-se ainda no caso de indenização devida por aquele que, no exercício de atividade profissional, por negligência, imprudência ou imperícia, causar a morte do paciente, agravar-lhe o mal, causar-lhe lesão ou inabilitá-lo para o trabalho.

\footnotetext{
${ }^{5}$ Ameaçar alguém, por palavras, escrito ou gesto, ou qualquer outro meio simbólico, de causar -lhe mal injusto e grave". Pena: Detenção de um a seis meses.

${ }^{6}$ Expor a perigo a vida ou a saúde de pessoa sob sua autoridade, guarda ou vigilância, para fim de educação, ensino, tratamento ou custódia, quer privando-a de alimentação ou cuidados indispensáveis, quer sujeitando-a a trabalho excessivo ou inadequado, quer abusando de meios de correção ou disciplina: Pena - detenção, de dois meses a um ano, ou multa.

${ }^{7}$ Difamar alguém, imputando-lhe fato ofensivo à sua reputação. Pena: detenção de três meses a um ano.

${ }^{8}$ Caluniar alguém, imputando-lhe falsamente fato definido como crime: Pena - detenção, de seis meses a dois anos, e multa.

9 Injuriar alguém, ofendendo-lhe a dignidade ou o decoro: Pena - detenção, de um a seis meses, ou multa.
} 
A atividade profissional médica, em regra geral ${ }^{11}$, constitui-se como obrigação de meio, ou seja, o agente se obriga a empreender a atividade, sem garantir, todavia, o resultado esperando. Entretanto, deve usar de prudência e diligências normais para a prestação devida do serviço, utilizando as melhores técnicas, objetivando alcançar um determinado resultado.

No que se refere aos profissionais que não integram o quadro permanente do hospital ou da clínica, mas que eventualmente utilizam a estrutura física e logística para realizar uma cirurgia, por exemplo, entende-se existir um liame jurídico entre o médico e a entidade hospitalar, de modo que há responsabilização objetiva da instituição, sem prejuízo de um eventual direito de regresso contra o médico. (GAGLIANO; PAMPLONA FILHO, 2015). Outros autores, entretanto, expressam que não há responsabilização do estabelecimento, respondendo o médico com exclusividade pelos seus erros, ressalvando-se os casos em que a causa única para a falha foi referente a equipamento disponibilizado pelo estabelecimento hospitalar. (GONÇALVES, 2015).

Quanto a responsabilidade subjetiva do médico, a jurisprudência já tem se manifestado:

Trata-se de agravo de instrumento contra decisão que negou seguimento a recurso extraordinário interposto de acórdão, cuja segue transcrita: APELAÇÃO CÍVEL. RESPONSABILIDADE CIVIL. DANOS MATERIAIS E MORAIS. LUCROS CESSANTES. PARTO NORMAL. EPISIOTOMIA. LASCERAÇÃO PERINAL DE $4^{\circ}$ GRAU. SUTURA DESCONTROLE NA ELIMINAÇÃO DE DEJETOS. INSUCESSO NA TENTATIVA DE CORREÇÃO. DANOS EVIDENTES. ERRO GROSSEIRO. IMPERÍCIA. NEGLIGÊNCIA. NEXO CAUSAL. CULPA RECONHECIDA. DEVER DE INDENIZAR. 1. Responsabilidade do médico: A relação de causalidade é verificada em toda ação do requerido, evidente o desencadeamento entre o parto, a alta premature e os danos físicos e morais, causando situação deplorável à apelante, originada de dilaceração perinal de $4^{\circ}$ grau. Configurado erro grosseiro, injustificável, com resultado nefasto, o qual teve por causa a imprudência $e$ negligência do requerido. Dever de indenizar.

2. Danos morais: evidentes, procedimento realizado de forma a técnica, causando sofrimento físico e moral, constrangimento, humilhação, angústia, impossibilidade de levar uma vida normal, desemprego, alto estresse familiar. Procedência. 3. Danos materiais: comprovados através de recibos e notas fiscais. Procedência. 4. Pensionamento: paralisação da atividade produtiva da vítima, enquanto perdurou o tratamento para reconstrução do períneo. Parcial procedência. DERAM PARCIAL PROVIMENTO AO APELO. (STF - AI: 810354 RS, Relator: Min. RICARDO LEWANDOWSKI, Data de Julgamento: 15/12/2010, Data de Publicação: DJe-001 DIVULG 04/01/2011 PUBLIC 01/02/2011, grifo nosso).

\footnotetext{
${ }^{10}$ Os artigos mencionados referem-se as devidas indenizações, respectivamente, nos casos de homicídio, lesão ou ofensa à saúde e impedimento de exercício de ofício ou profissão.

${ }^{11}$ Em se tratando de cirurgia plástica de natureza estética, haverá, segundo doutrina majoritária, obrigação de resultado, desta forma, o médico deverá produzir o resultado esperado. Em se tratando de cirurgia plástica reparadora, a exemplo dos casos de queimadura, a obrigação será de meio.
} 
O caso em tela apresenta uma prática associada a violência obstétrica: a episiotomia de rotina. Se feita de maneira indiscriminada e sem observância clínica pode ocasionar uma série de complicações. No julgado analisado sobreveio lasceração perinal de $4^{\text {o }}$ grau ocasionada pelo trauma obstétrico, resultando em incontinência fecal, o que perturbou o equilibrio emocional, social e psicológico da paciente.

A episiotomia é um dos únicos procedimentos realizados sem qualquer consentimento prévio do paciente. Conforme a pesquisa "Nascer no Brasil" estima-se que o procedimento seja realizado em 53,5\% dos partos via vaginal no Brasil, enquanto a recomendação da OMS é de 10\%. No caso de primíparas (primeiro filho), o índice chega a $74 \%$.

A cirurgia afeta diversas estruturas do períneo, tais como os músculos, vasos sanguíneos e tendões, gerando em alguns casos, incontinência urinária e fecal, além de provocar outras complicações, dentre elas a dor nas relações sexuais, risco de infecção e laceração perineal em partos subsequentes, maior volume de sangramento, além dos resultados estéticos insatisfatórios. (PREVIATTI; SOUZA, 2007).

Nesse sentido, resta clara a responsabilidade médica, bem como a fixação de valores a título de danos morais e materiais, além de pensionamento decorrente da paralisação do exercício laboral da vítima. Importante ainda salientar que poderá haver responsabilização solidária de todos os agentes que estejam ligados ao resultado danoso, desde que presente o elemento culpa.

Consoante Gagliano e Pamplona Filho "a prova do elemento anímico (culpa) é tão importante quanto a conduta humana equivocada, no que diz respeito aos deveres gerais como cidadão e aos específicos da atividade profissional”. (2015, p. 284).

Conforme observa Maria Helena Diniz:

\footnotetext{
Assim sendo, se o paciente vier a falecer, sem que tenha havido negligência, imperícia ou imprudência na atividade profissional da saúde, não haverá inadimplemento contratual, pois o médico não assumiu o dever de curá-lo, mas de tratá-lo adequadamente. [...]. Portanto, a responsabilidade civil dos médicos somente decorre de culpa provada, constituindo uma espécie particular de culpa. Não resultando provadas a imprudência ou imperícia ou negligência, nem o erro grosseiro, fica afastada a responsabilidade dos doutores em medicina, em virtude mesmo da presunção de capacidade constituída pelo diploma obtido após as provas regulamentares (TJRJ, ADCOAS, 1982, n. 84.019). (2007, p. 257).
} 
Desta forma, o erro médico consiste na falha profissional que resultou em dano. Além da responsabilização na esfera civil e/ou penal, o médico sujeita-se, ainda, as sanções administrativas do Conselho Federal de Medicina, podendo inclusive, dependendo da gravidade do dano, ser proibido de exercer o ofício. No que tange a culpa no cenário médico, Melo assevera que:

Tratando-se de erro médico e de responsabilização do profissional, a maior dificuldade residirá exatamente em fazer a prova de que o médico tenha agido com imprudência, negligência ou imperícia. Em muitas situações vai existir a lesão, o agente estará devidamente identificado, porém a impossibilidade de fazer a prova da culpa afastará o dever de reparação. (2014, p. 19).

A responsabilidade civil objetiva prevista na legislação consumerista, não se estende aos profissionais liberais. Entretanto, no que se refere a relação entre o hospital ou clínica médica que presta serviços, a responsabilidade civil é objetiva, por força do art. 932, III, do CC/2002: "São também responsáveis pela reparação civil: III - o empregador ou comitente, por seus empregados, serviçais e prepostos, no exercício do trabalho que lhes competir, ou em razão dele".

Enfatize-se que tal regra se estende também aos hospitais filantrópicos, uma vez que a atividade de cunho assistencial não afasta a responsabilidade de atender ao dever de informação e de responsabilizar-se pela falta de seu médico.

A Constituição Federal/88, em seu art. $37, \S 6^{\circ}$, expressa que: "as pessoas jurídicas de direito público e as de direito privado prestadoras de serviços públicos responderão pelos atos que seus agentes, nessa qualidade, causarem a terceiros", responsabilizando assim, objetivamente, a administração pública.

Seguindo tal diretriz, o art. 43 do CC/2002, registra que:

As pessoas jurídicas de direito público interno são civilmente responsáveis por atos dos seus agentes que nessa qualidade causem danos a terceiros, ressalvando direito regressivo contra os causadores do dano, se houver, por parte destes, culpa ou dolo.

Diante da responsabilidade civil do Estado, o acórdão analisado foi encontrado através da palavra-chave "episiotomia" no sítio do STF, julgado pela Segunda Turma, sendo o relator Ministro Celso de Mello, in verbis: 


\begin{abstract}
E $\quad M \quad E \quad N \quad T$ A: RESPONSABILIDADE CIVIL OBJETIVA DO PODER PÚBLICO - ELEMENTOS ESTRUTURAIS - PRESSUPOSTOS LEGITIMADORES DA INCIDÊNCIA DO ART. 37, § $6^{\circ}$, DA CONSTITUIÇÃO DA REPÚBLICA - TEORIA DO RISCO ADMINISTRATIVO - HOSPITAL PÚBLICO QUE INTEGRAVA, À ÉPOCA DO FATO GERADOR DO DEVER DE INDENIZAR, A ESTRUTURA DO MINISTÉRIO DA SAÚDE RESPONSABILIDADE CIVIL DA PESSOA ESTATAL QUE DECORRE, NA ESPÉCIE, DA INFLIÇÃO DE DANOS CAUSADA A PACIENTE EM RAZÃO DE PRESTAÇÃO DEFICIENTE DE ATIVIDADE MÉDICO-HOSPITALAR DESENVOLVIDA EM HOSPITAL PÚBLICO - LESÃO ESEINCTERIANA OBSTÉTRICA GRAVE - FATO DANOSO PARA A OEENDIDA RESULTANTE DE EPISIOTOMIA REALIZADA DURANTE O PARTO OMISSÃO DA EOUIPE DE PROEISSIONAIS DA SAÚDE EM REEERIDO ESTABELECIMENTO HOSPITALAR, NO ACOMPANHAMENTO PÓSCIRÚRGICO - DANOS MORAIS E MATERIAIS RECONHECIDOS RESSARCIBILIDADE - DOUTRINA - JURISPRUDÊNCIA - RECURSO DE AGRAVO IMPROVIDO. (STF, AI 852237 AgR, Relator(a): Min. CELSO DE MELLO, Segunda Turma, julgado em 25/06/2013, ACÓRDÃO ELETRÔNICO DJe-176 DIVULG 06-09-2013 PUBLIC 09-09-2013, grifo nosso).
\end{abstract}

Conforme se pode depreender houve responsabilização do poder público por meio da aplicação da teoria do risco administrativo, conforme postula Venosa:

[...] surge a obrigação de indenizar o dano, como decorrência tão só do ato lesivo e injusto causado à vítima pela Administração. Não se exige falta do serviço, nem culpa dos agentes. Na culpa administrativa exige-se a falta do serviço, enquanto no risco administrativo é suficiente o mero fato do serviço. (2001, p. 275).

Resta ainda salientar conforme lição de Melo que:

O fato de o serviço ser público e prestado de forma gratuita não isenta o hospital do dever de indenizar, na eventualidade de ocorrência de danos, porquanto há um dever de incolumidade ínsito na prescrição constitucional no que diz respeito à garantia fundamental à saúde e a vida das pessoas que "não subtrai o dever de a entidade hospitalar as segurar esses direitos sagrados do paciente. (2014, p. 148).

Por óbvio, nem todas as condutas relacionadas às práticas obstétricas podem ser enquadradas nessa modalidade de violência, ao passo que há situações de caráter emergencial que devem ser adotadas com escopo de salvar a parturiente e o nascituro.

Entretanto, condutas com relação à episiotomia devem ser analisadas com cautela e verificadas conforme depoimento nos autos a fim de averiguar se a gestante foi alertada do ato ou não. Analisando o inteiro teor do acórdão, podemos perceber que houve omissão do Poder Público em orientar a autora sobre o procedimento adotado no seu parto, assim como os eventuais riscos a que estaria exposta. Ademais, no caso em tela, temos o agravante da lesão que impede a parturiente ao convívio social normal. 
Nesse sentido, resta clara a violência obstétrica diante da perda de autonomia da parturiente em ser protagonista do seu parto, através de uma intervenção danosa que afetou consideravelmente sua qualidade de vida, prejudicando a sua integridade física, psíquica e sexual.

Desta forma, tem-se presente nos autos, todos os elementos caracterizadores para que seja imputada a responsabilidade civil objetiva do Poder Público, visto que há uma situação de fato que ensejou o evento danoso. Ademais, a ação ou omissão do agente público atenuada pela lesão à vítima, importa no dever do Estado em indenizar pelo dano moral e/ou material, independentemente da caracterização de culpa dos agentes estatais.

Importa ainda destacar, a partir da jurisprudência do STF os elementos que compõem a estrutura e delineiam o perfil da responsabilidade civil objetiva do Poder Público que compreendem:

(a) a alteridade do dano, (b) a causalidade material entre o 'eventus damni' e o comportamento positivo (ação) ou negativo (omissão) do agente público, (c) a oficialidade da atividade causal e lesiva, imputável a agente do Poder Público, que tenha, nessa condição funcional, incidido em conduta comissiva ou omissiva independentemente da licitude, ou não, do comportamento funcional (RTJ 140/636) e (d) a ausência de causa excludente da responsabilidade estatal (RTJ 55/503 - RTJ 71/99 - RTJ 91/377 - RTJ 99/1155 - RTJ 131/417). (STF, Ag. Reg. No Recurso Extraordinário 481.110-3 - DF. Min. Celso de Mello, Segunda Turma, julgado em 06/02/2007).

Quanto aos servidores públicos na condição de médicos, Ramos conclui que:

A responsabilidade direta e primária é do Estado; a do médico, como de todo servidor público, deve ser apenas indireta, recompondo o prejuízo sofrido pelo Estado, desde que provada sua culpa. (2008, p. 50).

Nesse sentido, a própria jurisprudência admite que:

PROCESSUAL CIVIL - RESPONSABILIDADE CIVIL DA ADMINISTRAÇÃO PÚBLICA. I - 'Se o erro ou falha médica ocorrer em hospital ou outro estabelecimento público, a responsabilidade será do Estado (Administração Pública), com base no art. 37, § 6º da Constituição Federal (...). (STJ, AC 278427, Rel. Juiz CASTRO AGUIAR - TRF/2 ${ }^{\mathrm{a}}$ Região, DJU de 22/08/2003, p. 255 - grifo nosso).

Frisa-se que os casos de lesão esfincteriana em decorrência de episiotomia tem alcançado os tribunais, em busca no sítio eletrônico JusBrasil foram encontrados 22 resultados.

Outro caso em que se faz presente práticas de violência obstétrica foi encontrado no sítio eletrônico do STJ através da palavra-chave "manobra de Kristeller". 


\begin{abstract}
ADMINISTRATIVO. AGRAVO REGIMENTAL. RESPONSABILIDADE CIVIL DO ESTADO. FALHA NA PRESTACÃO DE SERVICO MÉDICOHOSPITALAR. PARTO OUE RESULTOU EM SEOUELAS AO MENOR. PARALISIA CEREBRAL. USO DE FÓRCEPS (MANOBRA DE KRISTELLER). NEGATIVA DE PRESTAÇÃO JURISDICIONAL NÃO CONFIGURADA. DEVER DE INDENIZAR CARACTERIZADO. DANOS MORAIS. [...] (STJ, AgRg no AgREsp No 628542 - RJ. Min. Sérgio Kukina, Primeira Turma, julgado em 05/12/2015, grifo nosso).
\end{abstract}

A manobra de Kristeller, resultante de "pressões inadequadamente aplicadas ao fundo uterino no período expulsivo", constitui-se claramente prejudicial ou ineficaz e deve ser eliminada. (BRASIL, 2001, p. 188), sendo vedada pelo próprio sistema público.

Depreende-se assim, que o procedimento gera a concretização do dano no momento em que é empregado, uma vez que a execução por si só, contraria regra do Ministério da Saúde, cabendo, portanto, indenização a vítima lesada.

Salienta-se que em mais de um acórdão, encontramos a responsabilidade civil por erro médico, decorrente da aplicação da manobra de Kristeller, causando consequentemente, lesões ao neonato, tais como, distócia de ombro, e em outros casos paralisia cerebral, conforme julgado anterior.

Outra prática prejudicial com características claras de violência obstétrica é a proibição do acompanhante em consonância com a Lei 11.108/2005 que assegura tal direito às parturientes.

A Lei 11.108/2005 instituiu aos serviços de saúde do SUS, rede própria ou conveniada, obrigatoriedade em permitir a presença, junto à parturiente, de um acompanhante durante todo o trabalho de parto, parto e pós-parto imediato, sendo, o acompanhante, indicado pela gestante.

A pesquisa Nascer no Brasil à Escola Nacional de Saúde Pública Sergio Arouca (Ensp/Fiocruz), revelou que menos de $20 \%$ das mulheres se beneficiam da presença contínua do acompanhante durante todo o período de internação, sendo esse ainda um privilégio das mulheres com maior renda e escolaridade, brancas, usuárias do setor privado e que tiveram cesarianas como opção de parto.

Considera-se descumprimento do direito ao acompanhante quando: houver restrição da escolha da mulher; restrição do tempo de permanência do acompanhante ou ainda restrição pelo vínculo com a instituição, quando, por exemplo afirmam que tal direito só é válido para particulares. (PARTO DO PRINCÍPIO, 2012). 
Verifica-se, entretanto, que apesar da lei assegurar esse direito, algumas demandas são julgadas improcedentes:

\begin{abstract}
APELAÇÃO CÍVEL - AÇÃO DE INDENIZAÇÃO - HOSPITAL PÚBLICO REGIONAL - NASCIMENTO DE TRIGÊMEOS -ACOMPANHAMENTO DO PAI - IMPOSSIBILIDADE - MEDIDA EXCEPCIONAL - PECULIA RIDADES DO CASO - PRESTAÇÃO DO SERVIÇO - AUSÊNCIA DE ILICITUDE - DANO MORAL NÃO CARACTERIZADO - SENTENÇA MANTIDA. [...] O direito à presença de acompanhante durante o trabalho de parto, parto e pós-parto imediato está regulamentado desde 2005, pela Lei $\mathrm{n}^{\circ} 11.108$, no âmbito do SUS (Sistema Único de Saúde). Contudo, tal direito não prepondera na hipótese de haver risco à saúde das parturientes e dos nascituros. -Tratando-se de gestação de trigêmeos e sendo necessária a realização de cirurgia cesariana, com a presença de dois obstetras, um anestesista e três pediatras (um para cada recém-nascido) na sala cirúrgica, fez-se prudente limitar o acesso ao local, não havendo que se falar, portanto, em existência de conduta ilícita do corpo médico a ensejar dever de indenizar. - Recurso desprovido. (TJ/MG, Apelação Cível nº. 10027130028544001, Relator: Eduardo Andrade, $1^{\mathrm{a}}$ Câmara Cível, julgado em 15/07/2014).
\end{abstract}

Consoante exposto anteriormente, a responsabilidade penal também pode recair nos casos de violência obstétrica, independentemente da reparação dos danos na esfera civil. O caso abaixo refere-se a episiotomia que sem observância dos procedimentos adequados culminou com a morte da parturiente:

\begin{abstract}
APELAÇÃO CRIMINAL. HOMICÍDIO CULPOSO. Parto normal com episiotomia. ART. $121, \S 3^{\circ}$, DO cp. INCIDÊNCIA DA MAJORANTE DO $\S 4^{\circ}$ DO MESMO DISPOSITIVO LEGAL. (inobservância de regra técnica de profissão). Pena que não merece redimensionamento. Demonstrado que o réu agiu com negligência, imprudência e imperícia, e que dita conduta levou a paciente a óbito, pois, após o parto com episiotomia, deixou de realizar procedimento de revisão do reto, o que propiciou a comunicação do conteúdo fecal com o canal vaginal, culminando com infecção generalizada, que evoluiu com a morte da vítima, mostrase correta a sua condenação pela prática do delito de homicídio culposo. Aplicabilidade da causa de aumento de pena prevista no $\S 4^{\circ}$ do art. 121 do CP, por inobservância de regra técnica de profissão. Pena definitiva de dois anos de detenção, substituída por duas restritivas de direito, consistentes na prestação de serviços à comunidade e prestação pecuniária, que se mostra adequada ao caso, não ensejando redimensionamento. APELAÇÃO DESPROVIDA.(TJ/RS, Apelação crime $\mathrm{n}^{\mathrm{o}}$ : 70053392767, Relatora: DES. ${ }^{\mathrm{a}}$ Lizete Andreis Sebben, $2^{\mathrm{a}}$ Câmara Criminal, julgado em 14/11/2013).
\end{abstract}

Nesse caso, conforme observado, o acusado agiu com negligência, imprudência e imperícia, visto que deixou de fazer a revisão de toque retal após o procedimento de parto com episiotomia, momento em que teria diagnosticado a lesão a tempo de ser reparada. Ademais, procedeu alta à paciente, não obstante, suas reclamações de dor, o que gerou quadro de infecção generalizada "septicemia", culminando com o óbito, após vinte e cinco dias de internação em UTI hospitalar. A culpabilidade do réu é plena, por ser ele imputável e porque dele era exigida conduta diversa. 
Diante dos acórdãos analisados, resta clara a caracterização da violência obstétrica. Entretanto, apesar das normativas e regulamentos no âmbito do Ministério da Saúde com relação a temática, infelizmente, como já mencionado, não há no Brasil nenhuma legislação específica, nem no âmbito civil, nem no criminal, com relação a problemática, diferente do que ocorre na Argentina e Venezuela.

Entretanto, a ausência de legislação específica não impede que os aplicadores do Direito possam punir a prática, uma vez que resta caracterizada a violação de princípios e direitos basilares do Estado Democrático de Direito, podendo haver a aplicação da responsabilidade civil da equipe hospitalar e do Estado ou ainda aplicação da lei penal, conforme demonstrado.

Desta forma, é de extrema importância que as tendências caminhem no sentido de que o Direito seja utilizado como instrumento das lutas feministas para o reconhecimento da violência obstétrica como espécie de violência contra a mulher.

\section{CONSIDERAÇÕES FINAIS}

O presente artigo possibilitou averiguarmos a questão da responsabilidade civil e penal nos casos de violência obstétrica a partir da análise de julgados no âmbito do Supremo Tribunal Federal, Superior Tribunal de Justiça e Tribunais de Justiça dos Estados de Minas Gerais e Rio Grande do Sul.

A violência obstétrica como forma específica da violência de gênero deve ser reconhecida sobretudo através das decisões judiciais. Entretanto, os julgados sequer mencionam o termo "violência obstétrica", o que favorece a invisibilidade do fenômeno no curso do processo judicial.

Entretanto, isso não significa que não existam situações violadoras que caracterizam a prática, tendo em vista que há danos ou violências que ainda não são nomeadas ou compreendidas a partir da categoria "violência obstétrica", muitas parturientes e inclusive os operadores do direito ainda não têm compreensão acerca da temática. E isso pôde perfeitamente ser observado através dos julgados analisados que expressam situações caracterizadoras de violência obstétrica, sem contudo mencioná-la.

Embora timidamente, tais casos já encontram guarida na jurisprudência dos colendos tribunais, sendo caracterizada a responsabilidade civil objetiva do Poder público e 
subjetiva do médico, culminando na indenização por danos morais e materiais, bem como a responsabilidade penal.

Entretanto, apesar da possibilidade das responsabilizações, faz-se necessário que de fato a violência obstétrica seja reconhecida pelos agentes de justiça e seja mencionada nos julgados. Percebe-se, infelizmente, hipossuficiência técnica dos julgadores no sentido de caracterizar essa modalidade de violência.

Nesse sentido, faz-se mister ressaltar a importância de que em tais casos, os agentes do sistema de justiça, em especial, a magistratura, busquem analisar tais processos sob uma perspectiva de gênero, conforme os tratados internacionais de direitos humanos das mulheres.

Ademais, faz-se necessário pleitear a capacitação continuada dos magistrados e demais operadores do direito para que possam compreender melhor a temática a fim de que sejam proferidas decisões melhor embasadas tecnicamente e com as sanções devidas à gravidade dos casos trazidos em juízo. Além disso, o poder público deve investir na divulgação do tema por meio de políticas públicas de prevenção, para que as parturientes possam reconhecer tal modalidade de violência e saber a quem recorrer quando seus direitos forem lesionados.

Não se pode generalizar as condutas necessárias e emergenciais realizadas pelos profissionais de saúde, entretanto, nos julgados mencionados restou comprovado que o erro médico no momento do parto foi relacionado a práticas de violência obstétrica, tais como: episiotomia, uso de fórceps, manobra de Kristeller, violência psicológica e outras sequelas tanto ao neonato como a parturiente.

Diante da violação de preceitos amplamente assegurados pela Constituição Federal e do pleno reconhecimento dos danos morais e materiais, resta claro a possibilidade de reparação de danos plenamente indenizáveis, e, inclusive, a possibilidade de reparação dos danos estéticos analisando cada caso concretamente.

Infelizmente, os julgados ainda permanecem silentes diante da amplitude do panorama da violência obstétrica. Apesar da possibilidade de imputação da responsabilidade civil aos executores, bem como das devidas indenizações às vítimas, há ainda a difícil tarefa em comprovar o nexo de causalidade entre a conduta médico-hospitalar e o dano.

Ademais, as autoras, desejam, que de fato, a violência obstétrica seja reconhecida judicialmente e não encarada somente como erro médico, mas sim como uma violência de gênero específica. Resta expectar o momento em que haverá pelo menos um julgado que traz a verdadeira nomenclatura para um ato tão cruel. 


\section{REFERÊNCIAS}

BRASIL. Convenção Interamericana para Prevenir, Punir e Erradicar a Violência contra a Mulher, "Convenção Belém do Pará". Disponível em: < http://www.tjrj.jus. br/institucional/comissoes/cojem/cojem_convecao_interamericana_prevenir.pdf $>$. Acesso em:

21 dez. 2015.

. Código Civil. Vade Mecum Compacto. São Paulo: Saraiva, 2015.

Paulo: Saraiva, 2015.

Código de Defesa ao Consumidor (Lei 8.078/90). Vade Mecum Compacto. São

. Código Penal. Vade Mecum Compacto. São Paulo: Saraiva, 2015.

. Constituição Federal. Vade Mecum Compacto. São Paulo: Saraiva, 2015.

- Ministério da Saúde. Humanização do parto e do nascimento. Caderno

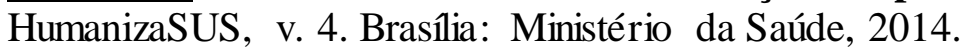

- Ministério da Saúde, Secretaria de Políticas de Saúde, Área Técnica de Saúde da Mulher. Parto, aborto e puerpério: assistência humanizada à mulher. Brasilia: Ministério da Saúde, 2001.

. SUPREMO TRIBUNAL FEDERAL. AI 810354 RS. Relator(a): Min. Ricardo

Lewandowski,. Brasilia, DF, 15 de dezembro de 2010. Disponível em: <http//

http://stf.jusbrasil.com.br/jurisprudencia/18006554/agra vo-de-instrumento-ai-810354-rsstf . Acesso em: 27 out. 2015.

. SUPREMO TRIBUNAL FEDERAL. AI 852237 AgR. Relator(a): Min. Celso de Mello. Brasilia, DF, 09 de setembro de 2013. Disponível em: <http://redir.stf.jus.

br/paginadorpub/paginador.jsp?doc TP=TP\&docID=4463295>. Acesso em: 27 out. 2015.

. .Supremo Tribunal Federal. Ag. Reg. no Recurso Extraordinário 481.110-3.

Relator(a): Min. Min. Celso de Mello. Brasília, 06 de fevereiro de 2007. Disponível em: < http://redir.stf.jus.br/paginadorpub/paginador.jsp?doc TP=AC\&docID=409350>. Acesso em:

23 dez. 2015.

. SUPERIOR TRIBUNAL DE JUSTIÇA. AgRg no AREsp 628542 / RJ.

$\overline{\text { Relator(a): }}$ Min. Sérgio Kukina. Rio de Janeiro, RJ, 05 de fevereiro de 2015. Disponível em:

$<$ https://ww2.stj.jus.br/processo/revista/documento/mediado/?componente=ATC\&sequencial $=44107550 \&$ num_registro $=201403165739 \&$ data $=20150213 \&$ tipo $=5 \&$ formato $=$ PDF $>$

. Acesso em: 23 dez. 2015.

DINIZ, Maria Helena. Curso de Direito Civil Brasileiro: responsabilidade civil. $21^{\mathrm{a}}$ ed. São Paulo: Saraiva, 2007.

GAGLIANO, Pablo Stolze; PAMPLONA FILHO, Rodolfo. Novo Curso de Direito Civil: responsabilidade civil. v. 3. 13 ${ }^{a}$ ed. São Paulo: Saraiva, 2015. 
GAGLIANO, Pablo Stolze; PAMPLONA FILHO, Rodolfo. Novo Curso de Direito Civil: parte geral. v. 1. $2^{\mathrm{a}}$ ed. São Paulo: Saraiva, 2002.

GONÇALVES, Carlos Roberto. Responsabilidade Civil. 10ª ed. São Paulo: Saraiva,

2015. KFOURI NETO, Miguel. Responsabilidade civil do médico. $8^{\text {a }}$ ed. São Paulo:

Revista dos

Tribunais, 2013.

MASSON, Cleber Rogério. Direito penal esquematizado: parte especial. $4^{\mathrm{a}}$ ed. Rio de Janeiro: Forense. São Paulo: Método, 2012, vol. 2.

MELO, Nehemias Domingos de. Responsabilidade civil por erro médico: doutrina e jurisprudência. 3. ed. São Paulo: Atlas, 2014.

MINAS GERAIS, Tribunal de Justiça. Apelação Cível no. 10027130028544001.

Relator: Eduardo Andrade, Minas Gerais, 15 de julho de 2014. Disponível em: < http://tjmg.jusbrasil.com.br/jurisprudencia/129091484/apelacao-civel-ac- 10027130028544001 mg?ref=topic_feed >. Acesso em: 26 mai. 2015.

ORGANIZAÇÃO MUNDIAL DE SAÚDE. Prevenção e eliminação de abusos, desrespeito e maus-tratos durante o parto em instituições de saúde. 2014. Disponível em: <http://apps.who.int/iris/ bitstream/10665/134588/3/WHO_RHR_14.23_por.pdf>. Acesso em: 04 nov. 2015.

PARTO DO PRINCÍPIO. Dossiê da Violência Obstétrica “Parirás com dor”. 2012. Disponível em:

$<$ http:/www.senado.gov.br/comissoes/documentos/SSCEPI/DOC\%20VCM\% 20367.pdf $>$. Acesso em: 10 dez. 2015.

PREVIATTI, Jaqueline Fátima; SOUZA, Kleyde Ventura de. Episiotomia: em foco a visão das mulheres. Revista Brasileira de Enfermagem, Brasilia, v. 60, n. 2, p. 197-201, mar./abr.

2007.

RAMOS, Itamar de Ávila. A responsabilidade civil dos estabelecimentos de saúde. Rio de Janeiro: Lamparina, 2008.

RIO GRANDE DO SUL, Tribunal de Justiça. Apelação crime $\mathbf{n}^{\mathbf{0}}$ : $\mathbf{7 0 0 5 3 3 9 2 7 6 7 .}$

Relatora: DES. ${ }^{a}$ Lizete Andreis Sebben. Porto Alegre, 14 de novembro de 2013.

Disponível em: < http:/tj-rs.jusbrasil.com.br/jurisprudencia/113388642/apelacao-crimeacr-70053392767- rs/inteiro-teor-113388652>

VENOSA, Sîlvio de Salvo. Direito Civil - parte geral. $3^{\text {a }}$ ed. São Paulo: Atlas, 2001. 